\title{
Sensitivity and specificity of the Yang Tobin Index to predict extubation success in critical patients
}

\author{
Alejandro Segura, $\mathrm{PT}^{1}$, Nathali Carvajal, $\mathrm{PT}^{1}$, Paola Andrea Chavarro, $\mathrm{PT}^{1}$, \\ Esther C. Wilches, $\mathrm{PT}^{2}$, Argemiro Carvajal, $\mathrm{BA}^{3}$
}

\section{SUMMARY}

Background: The Yang Tobin Index (Y/T) is a simple and objective measure to predict successful extubation. There are no Colombian studies supporting the use of $\mathrm{Y} / \mathrm{T}$ as a predictor of successful ventilator weaning.

Objective: To estimate the sensitivity and specificity of $\mathrm{Y} / \mathrm{T}$ as predictor of weaning and to evaluate the association with clinical and socio-demographic characteristics in adult patients at the intensive care unit.

Methods: Retrospective study. We analyzed a database of 332 records of patients under mechanical ventilation (MV) for more than 48 hours, from January 2006 to December 2007, with spontaneous breathing trial and measurement of Y/T before extubation.

Results: The sensitivity of $\mathrm{Y} / \mathrm{T}$ was $98.6 \%$, specificity $9.6 \%$, positive predictive value $85.4 \%$, negative predictive value $55.5 \%$. The cumulative incidence of successful extubation was $84 \%$. The greater incidence of unsuccessful extubation was associated with COPD (46.2\%). The MV time period showed a direct proportional relationship with failed extubation $(\mathrm{p}=0.186)$.

Conclusions: The $\mathrm{Y} / \mathrm{T}$ index is not a good predictor of success of extubation in the study population. No association was found between clinical and sociodemographic characteristics of the population, with respect to the sensitivity and specificity of the $\mathrm{Y} / \mathrm{T}$ as a predictor of success.

Keywords: Mechanical ventilation; Weaning; Breathing; Index.

Colomb Med. 2011; 42: 458-67

Sensibilidad y especificidad del Índice Yang Yobin para predecir el éxito del destete de la ventilación mecánica en pacientes críticos

\section{RESUMEN}

Introducción: El índice Yang Tobin (Y/T), es una medida sencilla y objetiva para predecir éxito en la extubación. A nivel nacional no existen estudios que sustenten el uso del índice como predictor de éxito de extubación.

Objetivos: Estimar la sensibilidad y especificidad del índice de Y/T y evaluar la relación con las características clínicas y demográficas en pacientes adultos en una unidad de cuidado intensivo.

Métodos: Estudio retrospectivo; se analizó la información consignada en 332 formatos de ventilación mecánica de los pacientes que recibieron soporte ventilatorio invasivo por más de 48 horas desde enero de 2006 a diciembre de 2007, con prueba de respiración espontánea y medición del índice Y/T antes de la extubación.

Resultados: La sensibilidad del Y/T fue 98.6\%, especificidad 9.6\%, valor predictivo positivo $85.4 \%$, valor predictivo negativo 55.5\%. La incidencia acumulada de extubación exitosa fue $84 \%$. La mayor incidencia acumulada de extubación no exitosa se asoció con EPOC (46.2\%). El tiempo de ventilación mecánica mostró una relación directamente proporcional con extubación no exitosa $(\mathrm{p}=0.186)$.

Conclusiones: El índice Y/T no es un buen predictor de éxito de la extubación en la población de estudio. No se encontró

1. Therapist Intensive Care Unit, Fundación Valle del Lili, Cali, Colombia. e-mail: seguralejo@hotmail.com nathali.carvajal@gmail.com paochava@hotmail.com

2. Assistant Professor, Faculty of Health, Coordinator of Specialization in Cardiopulmonary Physical Therapyirector of the Exercise and Cardiopulmonary Health Resarch Group, Universidad del Valle, Cali, Colombia. e-mail: esterwil@coorreounivalle.edu.co

3. Statistician in Health, Business Administrator, Universidad del Valle, Cali, Colombia. e-mail: angelmio69@yahoo.com Received for publication July 23, 2010 Accepted for publication February 22, 2011 
asociación entre características clínicas y sociodemográficas among them the proportion of extubation success, which de la población, con respecto a la sensibilidad y especificidad on the average was at $75 \%$, ranging from $45 \%$ to $98 \%$ del Y/T como predictor de éxito.

\section{Palabras clave: Ventilación mecánica; Destete; Respiración; Índice.}

Colomb Med. 2011; 42: 458-67

Mechanical ventilatory (MV) support is the base of the support treatment for acute respiratory insufficiency. However, its use beyond the necessary may mean greater possibility of nosocomial infection, atrophy of respiratory musculature, and increased hospital stay and costs. Due to the aforementioned, the process of ventilator weaning must be thought of early and timely during the evolution of a patient connected to Mechanical Ventilation. The traditional criteria for removal of mechanical ventilatory support include oxygenation measurements $\left[\mathrm{PaO}_{2}, \mathrm{PaO}_{2} / \mathrm{FiO}_{2}, \mathrm{D}(\mathrm{A}-\mathrm{a}) \mathrm{O}_{2}\right]$, mechanical (respiratory frequency, vital capacity, inspiratory pressure), ventilatory $\left(\mathrm{PaCO}_{2}, \mathrm{Vd} / \mathrm{Vt}\right)$ ventilation minute and ventilatory reserve ${ }^{1}$.

The Yang Tobin $(\mathrm{Y} / \mathrm{T})$ index and the activity of the respiratory center are also used, assessed with the occlusion pressure (P0.1). The Y/T index has shown the best prognosis capacity. The cut-off point that best predicts success is a $\mathrm{Y} / \mathrm{T}<100$ or 105 . The predictive values of the $\mathrm{Y} / \mathrm{T}$ index, obtained from Tobin's original study, were: positive predictive value $86 \%$, negative predictive value $82 \%$, sensitivity $97 \%$, specificity $64 \%$; unfortunately, subsequent studies have not found such a high construct validity ${ }^{2,3}$.

The study by Yang and Tobin (Y/T) reports that it was carried out with a small sample $(n=64)$, which were only grouped by medical pathologies, without bearing in mind the clinical condition, severity of the disease, and/or demographic characteristics, which could alter the validity of the study ${ }^{2}$.

The Y/T index is measured as the respiratory frequency/tidal volume; the values below 100 or 105 respirations per minute per liter suggest rapid shallow breathing is absent and that MV removal may be successful. Because it is easy to carry out, it is frequently used as a simple and objective measurement for ventilatory weaning.

Some studies have researched the predictive value of the Y/T index, reporting heterogeneity in the results,
In the bibliography consulted for this study, few Works supported the use of the Index bearing in mind the different groups of pathologies, age, severity of the disease, or total time of mechanical ventilation prior to trying the spontaneous breathing trial (SBT). Currently, at the national and regional levels the index continues being indiscriminately used, without bearing in mind some variables revolving around particular conditions of patients, even at the expense of not having bibliography available to substantiate its use as a predictor of extubation success in our population.

Given the increasing patient demand for MV, which surpasses 48 hours and the high complexity in a number of these patients, it is necessary to define the use of strategies to aid in predicting the most opportune moment for removal from mechanical ventilation, which also minimizes its costs and complications. The aim of this study was to estimate the sensitivity and specificity of the Y/T index in predicting extubation success in critical patients and to evaluate the relationship with the clinical and demographic characteristics.

\section{MATERIALS AND METHODS}

This retrospective study reviewed information consigned in the institutional record form denominated mechanical ventilation form applied to all adult patients with ventilatory support for over 48 hours, during the period from January 2006 to December 2007, at a fourth-level institution. Some 332 records were analyzed that complied with the inclusion criteria. The mechanical ventilation form includes demographic description, motive for intubation, clinical characteristics, time of mechanical ventilation, weaning process, extubation, and motive for re-intubation. This form is filled out on a daily basis and continually during each shift by physical therapists in charge of respiratory care.

Institutional protocol applied. All patients received ventilatory support with Servo 900 Maquel and Servo i Maquet ${ }^{\circledR}$ ventilators. The Institution's weaning protocol is founded on the criteria recommended by international guidelines: a) control or resolution of the cause motivating the $\mathrm{MV}$; b) $\mathrm{PaO}_{2} / \mathrm{FiO}_{2}>200 \mathrm{mmHg}$, $\mathrm{PaO}_{2}>60 \mathrm{mmHg}, \mathrm{PEEP} / \mathrm{CPAP}<5 \mathrm{~cm} \mathrm{H} \quad{ }_{2} \mathrm{O}, \mathrm{S}_{\mathrm{at}} \mathrm{O}_{2}$ $\geq 90 \%$. c) Adequate pulmonary mechanics: respiratory 
frequency below $35 \mathrm{rpm}$, tidal volume from 4 to $6 \mathrm{ml} /$ $\mathrm{kg}$; d) hemodynamic stability (dopamine $<5 \quad \mu \mathrm{g} / \mathrm{kg} /$ min), d) temperature $<38^{\circ} \mathrm{C}, \mathrm{Hb}>10 \mathrm{~g} / \mathrm{dl}$; e) normal serum electrolytes or correction of these prior to weaning; f) Glasgow $\geq 8$. Upon fulfilling these criteria, SBT was performed with the patient seated on the bed, with MV in support pressure mode (SPV), with SP of $7 \mathrm{CmH}_{2} 0$ and PEEP of $5 \mathrm{CmH}{ }_{2} 0, \mathrm{FiO}_{2} \leq 50 \%$ for a period from 30 to 120 minutes and when completing these, it was assessed if there were data of low tolerance, which are hereinafter described: a) Respiratory frequency $>35 \mathrm{rpm}$ or less than 8 for more than 5 minutes. b) $\mathrm{S}_{\mathrm{at}} \mathrm{O}_{2}<90 \%$ for more than 30 seconds, $\mathrm{PaO}$ $<60 \mathrm{mmHg}$, with $\mathrm{FiO}_{2} \leq 50 \%$. c) $\mathrm{FC}>140 \mathrm{lpm}$ or $20 \%$ increase of the basal value for more than 5 minutes. d) Systolic blood pressure $>190 \mathrm{mmHg}$ or $<90 \mathrm{mmHg}$ for over 1 minute under continuous monitoring or via repeated measurements. e) Presence of agitation, anxiety, or diaphoresis for more than 5 minutes. f) Diminished level of consciousness. g) Onset of signs of increased respiratory burden (use of accessory muscles, paradoxical pattern ${ }^{6}$.

Upon finishing SBT and before performing the extubation, the Y/T index was measured, making a relationship between the respiratory frequency and the tidal volume (in liters). If the index was below 100 or 105 , it was considered a good predictor to carry out extubation. Measurements were not made with other extubation predictors; the weaning protocol at the institution only includes the SBT and the Y/T index measurement. Extubation was considered failed when there was a need for re-intubation of the patient within the subsequent 48 hours.

Design of the instrument (ALNAPA). For the needs of this study, an ALNAPA form was designed, to fill o the variables of interest obtained from the institutional record form (mechanical ventilation form). The preliminary version of the ANALPA form was evaluated by a panel of four experts in caring for critical patients (two intensive care physicians and two physical therapists specialized in cardiopulmonary physical therapy) who analyzed the clarity and pertinence of the form and offered suggestions on how to improve the instrument. Once the corrections were made, the form had a pilot test with 10 records that would not be part of negatives were calculated based on a $2 \times 2$ contingency the study. The pilot test evidenced the need to eliminate table relating the $\mathrm{Y} / \mathrm{T}$ index variables (positive/negative) some variables that were not of interest for this research. vs. successful extubation (positive/negative).
In the bibliographic review carried out for this study no specific classification was found that would permit defining within categories the diversity of diseases and surgical interventions that motivated the mechanical ventilation; for this reason, to facilitate data processing and analysis, the research group, advised by four expert clinicians working at the institution where the research was conducted, defined the categories used for analysis of this study.

Inclusion criteria. Records from mechanical ventilation forms of adult patients who received invasive mechanical ventilatory support for more than 48 hours, and in whom the SBT conducted was successful in the SPV mode with support pressure of 7 CmIll and PEEP of $5 \mathrm{CmH}_{2} 0$, from 30 to 120 minutes, with measurement of the $\mathrm{Y} / \mathrm{T}$ index prior to extubation.

Exclusion criteria. The records of the mechanical ventilation forms of patients with tracheostomy and records with incomplete information were excluded from the study.

Ethics. This study, according to Norm 8430 Article 11 of 1993, is considered of minor risk, given that no type of intervention was performed. It was approved by Institutional Review Committee on Human Ethics at Universidad del Valle and by the Research Committee at the institution where the information was gathered.

Data analysis. The information collected in the ALNAPA form was arranged in a data base using the Excel program for Windows 2007. The statistical analysis was performed on the Epi-Info program version 6.4 and it was guided toward the measurement of indicators related to the «extubation success» effect, for which a description was made of each variable based on ratios, proportions, measurements of central uttendency and variability.

An ROC curve was constructed and the area under the curve was calculated. The continuous variables were expressed in means and the categories in proportion. For comparisons among continuous variables of normal distribution, we used the F statistic and the Chi square in the categories. A value of $p<0.05$ was considered statistically significant.

Values of sensitivity, specificity, positive predictive value, negative predictive value, false positives, and false 
Table 1

Probability ratios for the YIT Index

\begin{tabular}{|c|c|c|c|c|}
\hline & & \multicolumn{3}{|c|}{ Successful extubation } \\
\hline & & Yes & No & Total \\
\hline \multirow[t]{2}{*}{ Index } & Positive & 276 & 47 & 323 \\
\hline & Negative & 4 & 5 & 9 \\
\hline Total & & 280 & 52 & 332 \\
\hline
\end{tabular}

Sensitivity: 98.6

Specificity: 9.6

Positive predictive value: 85.4

Failure incidence: 15.7

Success incidence: 84.3

False positives: 14.5

Negative predictive value: 55.5

False negatives: 44.4

The ROC curve was used to estimate other cut-off points $(\mathrm{Y} / \mathrm{T}$ index value) for different values of sensitivity and specificity, seeking to find an optimal cut-off point that would indicate an acceptable discriminatory level of the test, however, the values of sensitivity or specificity were not improved.

\section{RESULTS}

We reviewed 2098 mechanical ventilation forms of adult patients who needed ventilatory support for more than 48 hours and who underwent SBT and measurement of the Y/T index, during the period January 2006 to December 2007; from these, we analyzed 332 forms that fulfilled the inclusion criteria. The following are the results obtained for each variable.

Sensitivity and specificity of the Yang Tobin Index. The Y/T index with a value below 100 or 105 was used as a predictor of extubation success, the following results were obtained: sensitivity $98.6 \%$, specificity

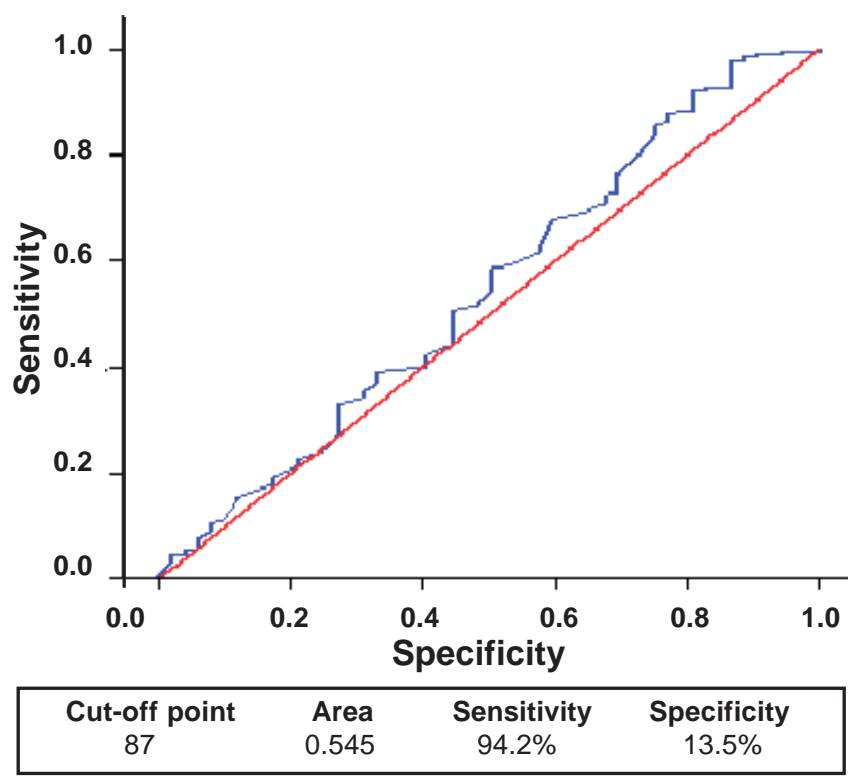

Graphic 1. ROC curve of the Y/T Index

$9.6 \%$, positive predictive value $85.4 \%$, negative predictive value $55.5 \%$, false positives $14.6 \%$, and false negatives $44.4 \%$ (Table 1 ).

ROC curve analysis. Bearing in mind the estimated indicators of sensitivity and specificity corresponding to the $\mathrm{Y} / \mathrm{T}$ index value, accepted as classification norm (105), and applying postulates of statistical normality, this study determined a new cut-off point $« \mathrm{C} »$ in the ROC curve with a value of 8 . The value calculated from the Y/T index (87), and the result indicated successful extubation when the index was below 87 , with a sensitivity of $94.23 \%$. The results revealed that in the «unsuccessful» extubation, the probability of a Y/T index value over 87 was of $13.5 \%$ (specificity) (Graphic 1).

Characteristics of the population. A total of 59\% (199) were men and 40.1\% (133) were women $(Z=$

Table 2

Characteristics of the study population

\begin{tabular}{lccc}
\hline Characteristics (mean + SD) & Men & Women & p \\
\hline Age (years) & $50.1 \pm 19.6$ & $56.1 \pm 17$ & 0.00458 \\
Height (cm) & $170.5 \pm 7.9$ & $155.7 \pm 7.2$ & 0.000001 \\
Weight (kg) & $66.3 \pm 7.2$ & $49.6 \pm 5$ & 0.000001 \\
Mechanical ventilation (hours) & $138.2 \pm 81.1$ & $126 \pm 79.6$ & 0.2711 \\
APACHE II >20 & $21.1 \pm 7.2$ & & \\
\hline
\end{tabular}




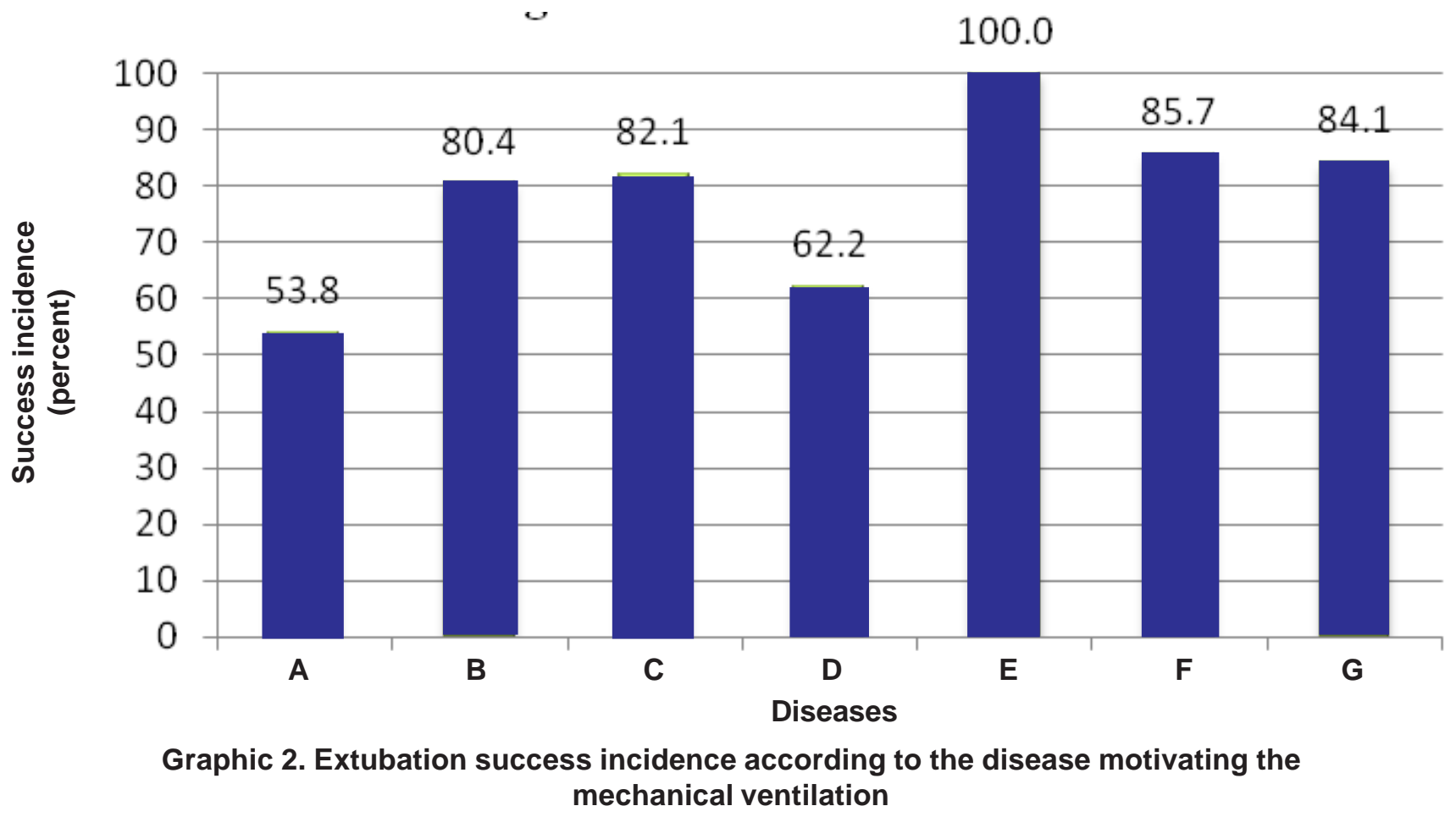

A: Chronic obstructive disease, B: Commitment of pulmonary parenchyma, C: Cardiovascular, D: Neurological, E: Neuromuscular, F: Gastrointestinal and metabolic, G: Sepsis.

3.61, $\mathrm{p}>\alpha=0.05)$. The age range was between 18 and 90 years, with a mean of 50.1 years for men and 56.1 for women. The study population was characterized for presenting significantly higher mean values for men in the variables of age, height, and weight (Table 2).

Relationship of the $Y / T$ index to clinical characteristics. The distribution of the different diagnoses and surgical interventions requiring MV for more than 48 hours was classified into seven medical categories and three surgical categories. Among the medical categories, the cardiovascular diseases occupied the first place with $23 \%$ (78), followed by the group of those compromising pulmonary mechanics with $20.8 \%$ (69), then sepsis with $19 \%$ (63). There were only two cases with neuromuscular disease.

The greatest incidence of extubation success according to the motive leading to MV was found in neuromuscular diseases (100\%), represented by two patients. Gastrointestinal, metabolic, endocrine, and autoimmune diseases had an incidence of extubation success greater than $80 \%$, while the greatest incidence of unsuccessful extubation was associated to the category of pulmonary obstructive diseases in 53.8\% (13) and the second place was occupied by neurological events and disease with $37.8 \%$ (37) cases.

The main motive for re-intubation was associated to increased respiratory burden in $65.3 \%$ (34), a third of the re-intubations were due to obstruction of the upper airway, followed by diminished level of consciousness. Only one case was related to respiratory acidosis.

The accumulated incidence of extubation success according to the disease motivating the MV was above $80 \%$ in all categories except for neurological diseases and chronic obstructive disease (Graphic 2). The highest accumulated incidence of extubation success according to the surgical intervention motivating MV was observed in the category of other surgical interventions (osteomuscular and neurological) with $94.9 \%$, followed by compromise in pulmonary mechanics in $91.3 \%$, and, finally, surgeries compromising the thoracic wall in $82.8 \%$.

Regarding patient height, sensitivity ranged between $96.2 \%$ and $100 \%$; the highest proportion of false positives was found in the 130- to 144-cm group (28.6\%) and $18.3 \%$ in the 145 - to $159-\mathrm{cm}$ group; the specificity values were very discrete, between 0 and $15 \%$, for the 
Table 3

Sensitivity and specificity of the $\mathrm{Y} / \mathrm{T}$ index according to clinical characteristics

\begin{tabular}{lcc}
\hline \multicolumn{1}{c}{ Clinical characteristics } & Sensitivity $\%$ & Specificity \% \\
\hline COPD & 100.0 & 0.0 \\
Commitment of the pulmonary parenchyma & 100.0 & 20.0 \\
Cardiovascular & 96.9 & 14.3 \\
Neurological & 95.6 & 0.0 \\
Neuromuscular & 100.0 & 0.0 \\
Gastrointestinal, metabolic & 100.0 & 0.0 \\
Sepsis & 98.1 & 20.0 \\
Commitment of the chest wall & 100.0 & 0.0 \\
Commitment in the pulmonary mechanics & 100.0 & 10.0 \\
Other surgical interventions & 94.6 & 0.0 \\
\hline
\end{tabular}

145- to $159-\mathrm{cm}$ group. Sensitivity of the index by groups of ideal weight reported values between $94.6 \%$ and $100 \%$, differences were not statistically significant. False positives represented nearly a quarter of the success results in the $45-$ to $49-\mathrm{kg}$ group and only $4 \%$ in off point of 87 .

the $65-$ to $69-\mathrm{kg}$ group.

Sensitivity of the index revealed values over $95 \%$ in all the clinical categories, while the specificity did not have values above $20 \%$ in any clinical characteristic (Table 3). Regarding the proportion of false positives, the highest value was noted in Chronic Obstructive Pulmonary Disease (COPD) $(46.2 \%)$ then in neurological diseases $(18.5 \%)$, followed by other surgical interventions (5.4\%), and no case was reported of neuromuscular diseases.

Sensitivity, according to age groups, reached its highest value (100\%) in patients from 30 to 59 years of age. The highest specificity value found in the study was related with the 30 - to 44-year age group (42.8\%). The findings we observed in this category were: of 47 patients, 7 failed extubation of which 3 had Y/T values $>105$ (correctly identified by the $\mathrm{Y} / \mathrm{T}$ index), and the three patients had a period of MV between 168 and 425 hours.

According to gender, the sensitivity for men was at $99.4 \%$, compared to women, which was $97.1 \%$ of the women ( $p>0.99)$. There is a positive relationship between the proportion of unsuccessful extubation and the time of MV, but this did not show statistically significant association $(\mathrm{p}>0.05)$ (Graphic 3 ). The $\mathrm{Y} / \mathrm{T}$ index revealed low discriminatory power for the successful extubation groups $(\mathrm{AVC}=0.545)$ and unsuccessful extubation, even when using a new cut-

\section{DISCUSSION}

Literature describes various predictors like occlusion pressure ( $\mathrm{p} 0.1$ ), the CROP index (ratio: compliance, respiratory frequency, oxygenation, pimax), the maximum inspiratory pressure (pimax), the vital capacity, and the Y/T index; being the Y/T index the most used as weaning predictor for successful and failed extubation ${ }^{3,9}$, but the scarce literature about the $\mathrm{Y} / \mathrm{T}$ behavior in patients from Latin American countries, with socio-demographic, ethnic, and cultural characteristics different from other population groups. Th\&/ $T$ index serves in evaluating the ventilatory capacity given that it quantifies rapid shallow breathing usually developed by patients who do not manage to get disconnected from ventilatory support.

Finding a good predictor for disconnection from ventilatory support has been a difficult task studied by many researchers ${ }^{2-4}$. Until now, a sole predictor has not been found to ensure success in ventilatory weaning, perhaps because several factors are associated at the moment of removing the ventilatory support. Johannigman et al. ${ }^{7}$, conducted a study seeking stra- 
tegies that permit identifying which patients were ready patients could not be successfully extubated.

to be disconnected from mechanical ventilation, to identify when extubation could take place, and how to predict the results of such extubation. The results revealed that analyzing these factors was not easy because of the passiveness of some clinicians who did not give importance to the decision of weaning, because of the aggressiveness of those performing premature extubations causing the need for re-intubation, and because of those who prolonged the days with unnecessary ventilatory support.

This study analyzed 332 forms from all the patients who were in MV for more than 48 hours, on whom an SBT had been performed by using the SPV mode with $7 \mathrm{CmH}_{2} \mathrm{O}$ and PEEP of $5 \mathrm{CmH}_{2} \mathrm{O}$, with a duration from 30 to 120 minutes; it should be noted that this method of performing the SBT differs substantially from the study by Yang and Tobin 2 in which the index was measured without mechanical ventilatory support (spontaneously breathing through a T-tube), reporting a specificity of $64 \%$, data which differs with those from this study where specificity was at $13 \%$.

Unfortunately, the data reported by some studies ${ }^{8}$ does not permit the clinician to determine the best balance between early and late weaning. One of the most important consequences left by failed extubations is nosocomial pneumonia and increased mortality; and on the other hand, maintaining unnecessary ventilatory support places the patient at risk of acquiring infections and other complications.

Esteban et al. ${ }^{9}$ conducted a multi-centered, prospective cohort study in intensive care units of European and Latin American countries, where they found that the mean time of MV was of 5.9 days, similar data to that in this study where the mean time was 5.8 days (138.2 hours) for men and 6.2 days (148.1 hours) for women.

There is no homogeneity in the data reported about the reliability of the Y/T index. Another studymentions that this index is an unreliable instrument. These differences could be explained by the time of MV, nutritional state, severity of the disease, and poor physical condition ${ }^{11}$.

Capdevila et al. ${ }^{12}$ found significantly low values of $\mathrm{Y} / \mathrm{T}(50+23$ vs. $69+25$ respirations/min/l) in patients with successful extubations; however, other authors ${ }^{16}$ reported higher values or equal to 57 with which the
Lee et al. ${ }^{11}$ prospectively analyzed 52 patients on whom they performed an SBT in the presence of PS or CPAP; the index was measured after one hour of being in the weaning mode. The results revealed that extubation was successful in 31 patients with $\mathrm{Y} / \mathrm{T} \leq 105$ and in 12 patients with $\mathrm{Y} / \mathrm{T}>105$. The authors used the index with a threshold below or equal to 105 as an indicator of extubation success, finding sensitivity of $72 \%$ and specificity of $11 \%$, with a positive predictive value of $79 \%$ and a negative predictive value of $8 \%$; with these results it was concluded that the presence of the $\mathrm{Y} / \mathrm{T}$ index above 105, measured during an SBT with the patient connected to MV in SPV mode, did not discriminate those patients who would probably fail the extubation. The results of the current study found sensitivity at $98.5 \%$ and specificity at $9.6 \%$, similar data to the study by Lee et al. ${ }^{11}$ in spite of the methodological differences between them.

The low specificity of the index, reported in this study, may be associated to the measurement during ventilatory support, which could mask patients who were in a state of borderline recovery subjacent to their base disease and in whom a small ventilatory support was sufficient to classify them as positive for PRE, with an index $<105$, but who upon removal from ventilatory support failed the extubation.

Some studies describe the performance of the SBT with diverse methodologies showing differences in the thresholds of the $\mathrm{Y} / \mathrm{T}$ index. Some studies perform the SBT in the presence of partial ventilatory support ${ }^{13}$.

Mohamad et al. ${ }^{14}$ measured the $\mathrm{Y} / \mathrm{T}$ index with various levels of ventilatory support prior to extubation, rthey compared the results of the index when the patient was breathing in SPV mode with PS $5 \mathrm{CmH}_{2} \mathrm{O}$, PEEP $5 \mathrm{CmH}_{2} \mathrm{O}, \mathrm{FiO}_{2}$ at $40 \%$; in PS $0 \mathrm{CmH}{ }_{2} \mathrm{O}$, PEEP 5 $\mathrm{CmH}_{2} \mathrm{O}, \mathrm{FiO}_{2}$ at $40 \%$ (CPAP); and in $\mathrm{PS} 0 \mathrm{CmH}{ }_{2} \mathrm{O}$, PEEP $5 \mathrm{CmH}_{2} \mathrm{O}, \mathrm{FiO}_{2}$ at $21 \%$ (CPAP - ambient airdnd one minute breathing spontaneously through a T-tube, the $\mathrm{Y} / \mathrm{T}$ index was significantly lower in patients receiving PS $(46 \pm 8 \mathrm{rpm} / \mathrm{l})$ vs. T-tube $(100 \pm 23 \mathrm{rpm} / \mathrm{l})$. The authors in this study concluded that programming ventilatory support when performing an SBT alters the result of the index, and the threshold proposed by Yang and Tobin should only be used when the patient has been completely removed from ventilatory support and the trial is being performed through a T-tube. 
Similar findings have been found by previous studies $^{8,9}$, which have reported that using PS increases the tidal volume with a concomitant decrease of the respiratory frequency producing a significant reduction of the ratio: Respiratory frequency/Tidal volume $(\mathrm{F} /$ $\mathrm{Vt})$. Using PS during an SBT has been studied in terms of decreasing respiratory muscle work. Johannigmart $a l .{ }^{7}$ evaluated the effectiveness of the $\mathrm{Y} / \mathrm{T}$ index as an estimator of respiratory work during an SBT at different $74 \%$. levels of PS; they found diminished respiratory work and Y/T index result as PS levels increased. Results such as these increase the possibility of false positives when performing an SBT in the presence of SPV because the clinician could infer extubation success. Regarding specificity of the index in this study, the rate of false positives was of $14.4 \%$. Another study observed variability in this finding. These differences may be due, besides the difference in the cut-off points used, to methodological modifications, the moment in which the respiratory frequency is measured and the tidal volume, the duration of the MV, and the characteristics of the patients. In this study, the Y/T index did not show good discriminatory power for extubation success, even when using another cut-off point $(87 \mathrm{r} / \mathrm{min} / 1)$, the behavior compared to the study mentioned was similar for sensitivity of $94.2 \%$ and specificity of $13.5 \%$.

The Acute Physiology and Chronic Health Evaluation (APACHE II) is one of the most frequently used systems to quantify the gravity of a patient independent of the diagnosis. Based on this score, we can predict the evolution of patients through an objective score. The Apache II found in the postulation of this study was of $21.1+7.2$, which indicated mortality percentage close to $40 \%$. This index of severity of the disease has been proposed as a predictor of successful or failed extubation, and some studies report higher APACHE II scores increase the probability of failed extubation ${ }^{16,17}$.

The results in this study revealed that the highest incidence of unsuccessful extubation was associated to the category of pulmonary obstructive diseases in $46.2 \%$ (13) of the cases; this may have been related to mechanical disadvantage, high energy expenditure, and -in many cases- malnutrition of these patients, which predisposes respiratory fatigue after a few hours of being removed from ventilatory support ${ }^{17}$.
In this study, for the unsuccessful extubation group, the mean value for the index was $58.9 \mathrm{r} / \mathrm{min} / 1$ with a deviation of 27.54, very similar to the study by Frutos et $a l .{ }^{13}$ in which a Y/T index above $57 \mathrm{r} / 1 / \mathrm{min}$ was determined as a risk factor for unsuccessful extubation. In a study by Danagaet al. ${ }^{18}$ a Y/T cut-off value $>76.5$ was determined as predictive of risk for unsuccessful extubation, with a sensitivity of $66 \%$ and specificity of

Jiménez et al. ${ }^{19}$ found significant differences among groups of successful and failed extubations in the number of days of MV $(p=0.002)$ finding a ratio between the failed extubations and a greater number of days of MV and sedation, as well as with mortality. Estebanet al. ${ }^{20}$ demonstrated that mortality is greater when increasing the number of hours of $\mathrm{MV}$, in part due to associated complications like, pneumonia associated to the ventilator and trauma of the airway.

Fontela et al. ${ }^{21}$ relate the time of MV as a risk factor for unsuccessful extubation, data which coincide with the results from this study. Tanioset al. ${ }^{22}$ evaluated the effect of including the $\mathrm{Y} / \mathrm{T}$ index in a weaning protocol. These authors observed that including this index with the cut-off point initially described (105 resp/min/l) significantly increased the duration time of the weaning ( 3 days against 2 days in patients in which the index was used to make the decision of extubating; p: 0.04), the authors did not find differences regarding unsuccessful extubation or rate of intra-hospital mortality. This study suggests that the demand for strict compliance of the criteria for weaning may prolong the use of MV.

Until now, it has not been possible to find a sole predictor for extubation success, given the many factors to bear in mind when removing the patient from MV, above all those with prolonged MV. Although this was not a main objective of the study, we recommend an adequate and thorough evaluation of the patient to facilitate and complement the prediction of extubation success. Difficult aspects to evaluate like the level of consciousness, scarce amount of secretions, adequate cardiovascular reserve, and respiratory muscle strength are essential to ensure extubation success.

Various aspects in conducting this study must be carefully considered: a) there was no analysis made of successful or unsuccessful extubation related to the severity of the disease according to Apache II and according to the time on mechanical ventilation, b) due 
to incomplete recording of the information on the mechanical ventilation form, many cases did not comply with the inclusion criteria, c) the difficulty in classifying ${ }^{1}$ the categories of the events motivating the MV.

It is considered that the results obtained by this study serve as a foundation for other research related to weaning and extubation criteria in our realm.

\section{CONCLUSIONS}

- The results from this study suggest that the Y/T index is not a good predictor of extubation success in the population studied.

- No associations were found among clinical and socio-demographic characteristics with the sensitivity and specificity of $\mathrm{Y} / \mathrm{T}$ as a predictor of success in ventilatory weaning.

- In the 332 records of adult patients subjected to MV for over 48 hours with SBT and Y/T measurement prior to extubation, the estimated incidence of successful extubation was at $84 \%$.

- The main motive for re-intubation was associated to increased respiratory burden in $65.3 \%$ of the cases.

- The decision to wean patients from MV requires a comprehensive evaluation by a medical team and must bear in mind that although patients often fulfill all or much of the criteria recommended by international guidelines, it is still a challenge. This has favored the use, often indiscriminate, of predictive indices, to aid in the clinical decision. However, caution should be taken to avoid routine and unwavering use of the indices because they are merely that: predictors but never definers of extubation. Conflict of interest. None of the authors has conflicts of interest related to this study.

\section{ACKNOWLEDGEMENTS}

Financing Fundación Valle del Lili. We thank Universidad del Valle, Fundación Valle del Lili, the Head and Coordinator of the Department of Respiratory Therapy Olga Chapetón and Patricia Hernández, the Group of Physical Therapists at the ICU, the Chief of Adult ICU Dr. Marcela Granados and Dr. Marisol Badiel, Director of the Institute of Clinical Research.

\section{REFERENCES}

1. Brito B, Brugada R, Gayosso O. Indice de respiraciones superficiales rápidas para predecir el éxito del destete de la ventilación mecánica en pacientes críticos. Rev Asoc Mex Med Crit Ter Int. 1999; 12: 76-80.

2. Yang KL, Tobin A. prospective study of indexes predicting the outcome of trials of weaning from mechanical ventilation.Engl J Med.1991; 324: 1445-50.

3. Meade M, Guyatt G, Cook D, Griffith L, Sinuff T, Kergl eț al. Predicting success in weaning from mechanical ventilation. Chest. 2001; 120: 400-24.

4. Zeggwagh AA, Abouqal R, Madani N, Zekraoui A. Weaning from mechanical ventilation: a model for extubation. Intensive Care Med. 1999; 25: 1077-83.

5. Tobin MJ, Jubran A. Variable performance of weaning-predictor tests: role of Bayes' theorem and spectrum and test-referral bias. Intensive Care Med. 2006; 32: 2002-12.

6. Fundación Valle del Lili. Guía terapéutica de destete de la ventilación mecánica y extubación GT-TER-017. Cali: Fundación Valle del Lili; 2007.

7. Johannigman JA, Kenneth D, Campbell R, Branson R, Luchette, F, Hurst J. Use of the rapid/shallow breathing index as an indicator of patient work of breathing during pressure support ventilation. Surgery. 1997; 122: 737-41.

8. Brochard L, Rauss A, Benito S, Conti G, Mancebo J, Rekik N $\$$ t al. Comparison of three methods of gradual withdrawal from ventilatory support during weaning from mechanical ventilation. Am J Respir Crit Care Med. 1994; 150: 896-903.

9. Esteban A, Frutos F, Tobin MJ, Alia I, Sotsoma JF, Vallverdú I, et al. A comparison of four methods of weaning patients from mechanical ventilation. $N$ Engl J Med. 1995; 332: 345-50.

10. Epstein SK. Weaning from ventilatory support. Curr Opin Crit Care. 2009; 15: 36-43.

11. Lee K, Hui K, Chan T. Rapid shallow breathing frequency-tidal volume ratio did not predict extubation outcome. Chest. 1994; 105: 540-3.

12. Capdevila XJ, Perrigault PF, Perey PJ, Roustan JP, D'Athis F. Occlusion pressure and its ratio to maximum inspiratory pressure are useful predictors for successful extubation following T-piece weaning trial. Chest. 1995; 108: 482-9.

13. Frutos F, Esteban A, Epstein SK, Arabi Y, Apezteguía C. Risk factors for extubation failure in patients following a successful spontaneous breathing trial. Chest. 2006; 130: 1664-71.

14. Mohamad F, El K, Salah M, Ghassan W. Effect of pressure support ventilation and positive end expiratory pressure on the rapid shallow breathing index in intensive care unit patients. Intensive Care Med. 2008; 34: 505-10.

15. Esteban A, Alia I, Gordo F, Fernández R, Solsona JF, Vallverdu $\mathrm{I}$, et al. Extubation outcome after spontaneous breathing trials with T-tube or pressure support ventilation. Am J Respir Crit Care Med. 1997; 156: 459-65.

16. Knaus WA, Draper EA, Wagner DP, Zimmerman JE. APACHE II: a severity of disease classification system. Crit Care Med. 1985; 10: 818-29.

17. Afessa B, Hogans L, Murphy R. Predicting 3-day and 7-day outcomes of weaning from mechanical ventilation.Chest. 1999; 116: 456-61. 
18. Danaga, A, Gut A, Dos Anjos A, Yamaguti F, Christovan J, Teixera U. Avaliaçao do desempenho diagnóstico e do valor de corte para o índice de respiraçao rápida e superficial na prediçao do insucesso da extubaçao. J Bras Pneumol. 2009; 35: 541-7.

19. Jiménez G, Barragán JR, Aguilera M.C, Garza AG, Maltos W. Incidencia de failed extubations y risk factors concomitantes en patients de la unidad de terapia intensiva pediátrica: experiencia en un hospital universitario. Med Univer. 2007; 9: 7-12.

20. Esteban A, Anzueto A, Frutos F, Alía I, Brochard L, Stewart E, et al. Characteristics and outcomes in adult patients receiving mechanical ventilation a 28 -day international study.

JAMA. 2002; 287: 345-55

21. Fontela PS, Piva JP, García PC, Bered PL. Risk factors for extubation failure in mechanically ventilated pediatric patients. Pediatr Crit Care Med. 2005; 6: 166-70.

22. Tanios MA, Nevins ML, Hendra KP, Cardinal P. A randomized controlled trial of the role of weaning. Predictors in clinical decision making. Crit Care Med. 2006; 34: 1-10. 